\title{
Retroperitoneal kistik lenfajiom
}

\author{
Retroperitoneal cystic lymphangioma
}

Orhan ÇOŞKUN ${ }^{1}$, Muhammet Yener AKPINAR ${ }^{1}$, Erkin ÖZTAŞ ${ }^{1}$, Serkan TORUN², Bülent ÖDEMIŞ

Türkiye Yüksek Ihtisas Eğitim ve Araştırma Hastanesi, ${ }^{1}$ Gastroenteroloji Kliniği, Ankara

Bartın Devlet Hastanesi, ${ }^{2}$ Gastroenteroloji Kliniği, Bartın

Kistik lenfanjiomlar, lenfatik sistemin nadir görülen, benign, yavaş büyüyen lezyonlarıdır. Semptomlar kistin büyüklügüne, lokalizasyonuna ve gelişebilecek olan komplikasyonlara bağlı olarak değişik karakterde olabilirler. Radyolojik bulgular ve iğne aspirasyon biyopsisi kistik lenfanjiomları diğer kistik lezyonlardan ayrt etmede yetersiz kalmaktadır. Bu nedenle pankreatik lenfanjiomun kesin tanısı cerrahi eksizyon ve histopatolojik inceleme ile konulabilir. Karın ağrısı yakınması ile başvuran ve tetiklerinde retroperitoneal alanda kistik lezyon saptanan bir lenfanjiom olgusunu sunuyoruz.

Anahtar kelimeler: Lenfanjiom, psödokist, retroperitoneal kist
Cystic lymphangiomas are rare and slow-growing benign tumors of the lymphatic system. Symptoms of cystic lymphangiomas vary and are generally associated with the location, size, and complications of the cyst. Imaging methods and needle aspiration biopsies remain inutile in making a diagnosis of cystic lymphangioma. For this reason, surgery and histopathologic examination are necessary to make a definitive diagnosis of cystic lymphangioma. Here, we present a case who was admitted to our hospital with abdominal pain and diagnosed with cystic lymphangioma.

Key words: Lymphangioma, pseudocyst, retroperitoneal cyst

dıştan bası yapan lezyon görüldü (Resim 2). Üst abdomen magnetik rezonans (MR) incelemesinde pankreas kuyruk kesimi anteriorunda $97 \times 60 \mathrm{~mm}$ boyutlarında Tl'i hipointens, T2'si hiperintens kontrast tutulumu göstermeyen kistik görünüm saptandı (Resim 3). Endosonografik (EUS) incelemede kist çevresinde mide duvar katları izlenmedi (Resim 4). Yoğun içeriği olan kistten ince iğne aspirasyon biyopsisi (IIAB) ile örnek alındı. Aspire edilen sıvı açık sarı renkte olup amilaz: 33 U/L, CEA:1.68, CA 19-9: <0.8 ve Lipaz: 6 U/L bulundu. Aspire edilen sıvının sitolojik incelemesi benign olarak bulundu.

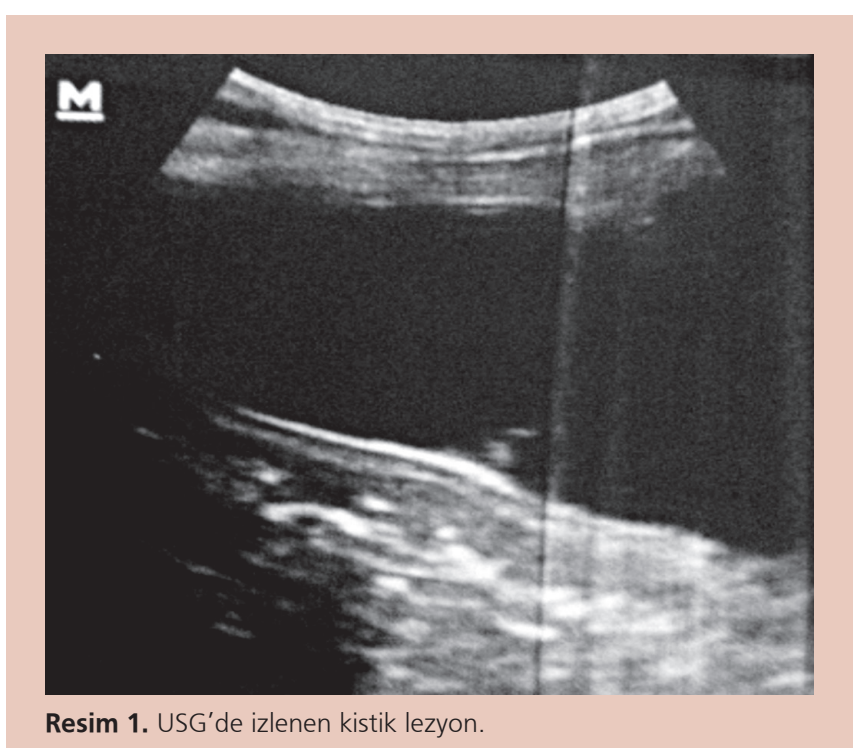

İletişim: Orhan ÇOŞKUN Türkiye Yüksek İhtisas Eğitim ve Araştırma Hastanesi, Gastroenteroloji Kliniği, Kızılay Caddesi, Sıhhiye, 06100, Ankara Tel: +90 31230613 20•Fax: +90 31231241 20•E-mail: drocoskun79@gmail.com Geliş Tarihi: 28.03.2017 Kabul Tarihi: 14.04.2017 


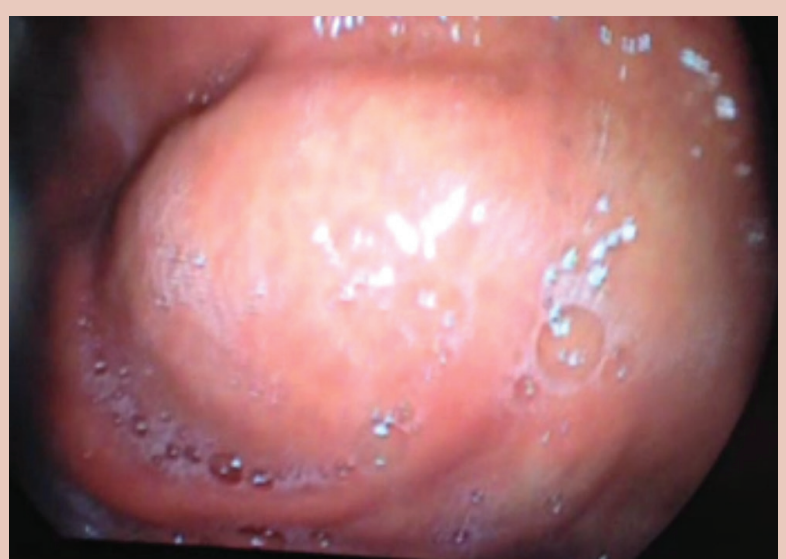

Resim 2. Gastroskopide mide korpusuna dıştan bası.
EUS bulguları ile gastrik duplikasyon kisti dışlandı. Kist sıvısının amilaz düzeyinin düşük olması ile psödokist dışlandı. Kesin tanısı konulamayan hasta gastroenteroloji-gastroenteroloji cerrahi konseyinde tartışılarak operasyon kararı alındı. Operasyonda mide küçük kurvaturdan başlayıp pankreas gövde kısmina uzanan $12 \times 10 \mathrm{~cm}$ boyutunda, mobil kistik lezyon saptandı ve frozen incelemesinde malignite dişlandı. Kistik lezyon çıkarılarak yapılan histolojik incelemesinde tanısı benign hamartomatöz lezyon (lenfanjiom) ile uyumlu bulundu.

\section{TARTISQMA}

Retorperitoneal alanda görülen en sık kistik lezyon pankreatik psödokisttir. Ayrıca pankreasın seröz ve müsinöz kistleri, kistadenokarsinomları, kistik mezotelyoma, teratom, over

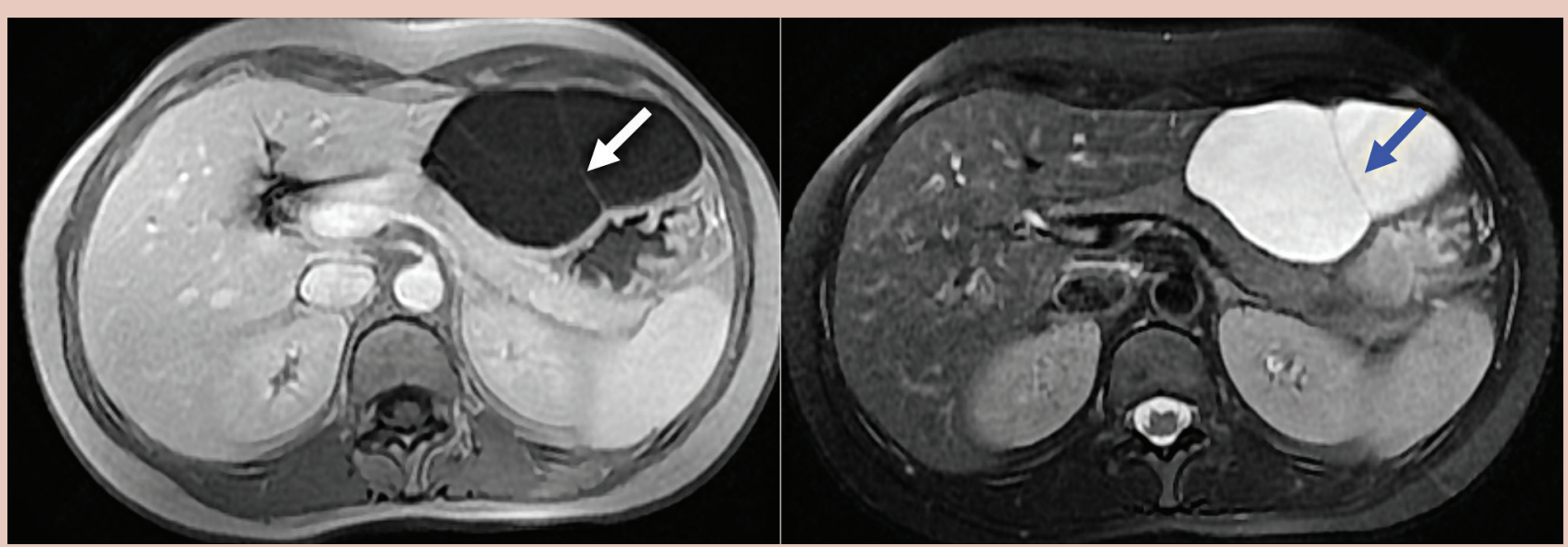

Resim 3. MR'da T1 hipointens, T2 hiperintens görünen ve ince septa içeren (ok) kistik lezyon.

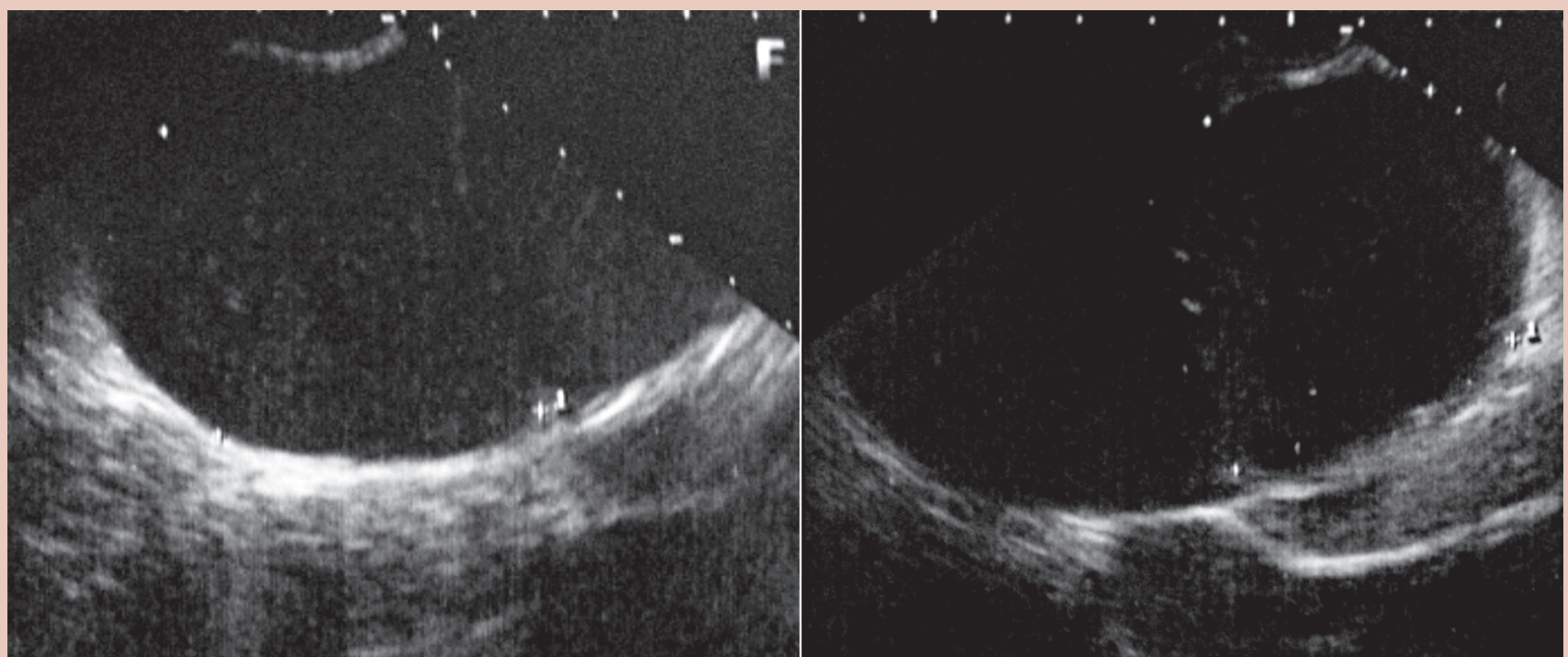

Resim 4. Kistin endosongrafik görünümü. 
veya gastrik tümörlerin kistik metastazları ve kistik lenfanjiomu da içeren retroperitoneal hamartomlar görülür (4). Kistik lenfanjiomlarda tümör boyutu 3-20 cm arasında değişebilir (ortalama $12 \mathrm{~cm}$ ) (5). Wegner histolojik olarak lenfajiomları kapiller, kavernöz ve kistik lenfanjiom olarak 3 kategoriye ayırmıştır. Retroperitoneal lenfanjiomlar çoğunlukla kistik tiptedir (4). Lenfanjiomların klinik bulguları özgül değildir. Genellikle büyüklüklerine bağl klinik semptomlarla ortaya çıkabilir olsalar da hiçbir bulgu vermeden tesadüfen saptanabilirler (5). Ultrasonografi (US), bilgisayarlı tomografi (BT), MR gibi görüntüleme çalışmalarına ek olarak, sitolojik değerlendirme için EUS ve ince iğne aspirasyonu (EUS-FNA) tanı sağlamamıza yardımcı olabilir (6). Radyolojik görüntüleme yöntemlerinde iyi sinırlı, ince duvarlı ve septasyonlar içerebilen kistik lezyonlar olarak tanımlanırlar (7). Kistik lenfanjiomalarda görüntülemenin değeri, maligniteyi dışlamak ve cerrahiden önce tümörün tam anatomik yerini sunmaktır (3).

\section{KAYNAKLAR}

1. Gachabayov M, Kubachev K, Abdullaev E, et al. A Huge cystic retroperitoneal lymphangioma presenting with back pain. Case Rep Med 2016;2016:1618393

2. Sohn BK, Cho CH, Chae HD. Cystic lymphangioma of the pancreas. J Korean Surg Soc 2011;81:141-5.

3. Lepre L, Costa G, Cortese F. Emergency presentation of cystic lymphangioma of the colon: A case reportand literatüre review. Int J Surg Case Rep. 2016;24:162-5.

4. Kumar SS, Das SA, Kate V. Cystic lymhangioma of the lesser sac in adult presenting with features of gastric outlet obstruction - A case report. J Clin Diagn Res 2015;9:PD15-6.
Ancak bizim olgumuzda olduğu gibi çoğu vakada radyolojik ve sitolojik yöntemler ile ayırıcı tanıya varılamaz ve kesin tanı cerrahi eksizyon sonrası histopatolojik inceleme ile konur (5). Karakteristik radyografi özellikleri ve klinik bulgularının bulunmadığı durumlarda pankreatik kistik neoplazmlar, psödokist olarak yanlış sinıflandırılabilir (8). Pankreatit öyküsü olmayan hastanın kist içeriğinden çalışılan amilaz düzeyinin normal olması nedeniyle hastada pankreatik psödokist düşünülmedi. Ayrıca EUS'ta mide duvar katları izlenmediği için gastrik duplikasyon kisti tanısından da uzaklaşıldı. Kist sıvısı sitolojik incelemesinde malign hücre saptanmayan hastada kesin tanı konulamadığı için cerrahi kararı alındı. Histopatolojik inceleme ile hastanın kesin tanısı konuldu.

Kistik lenfanjiomlar nadir görülen tümörler olmakla beraber retroperitoneal alanda sik görülen psödokist gibi diğer kistik lezyonların ayırıcı tanısında dikkate alınmasını öneririz.

5. Santes O, Chan C. Cystic lymphangioma of the pancreas: a rare entity. J Gastrointest Surg 2016;20:2100-1.

6. Talaiezadeh A, Ranjbari N, Bakhtiari M. Pancreatic lymphangioma as a rare pancreatic mass: A case report. Iran J Cancer Prev 2016;9:e3505.

7. Macin G, Hekimoglu K, Uner H, Tarhan C. Pancreatic cystic lymphangioma: diagnostic approach with MDCT and MR imaging. JBR-BTR 2014;97:97-9

8. ASGE Standards of Practice Committee, Muthusamy VR, Chandrasekhara $\mathrm{V}$, Acosta RD, et al. The role of endoscopy in the diagnosis and treatment of cystic pancreatic neoplasms. Gastrointest Endosc 2016;84:1-9. 